\title{
Effect of genistein and daidzein on platelet aggregation and monocyte and endothelial function
}

\author{
Nicole Gottstein ${ }^{1}$, Benjamin A. Ewins ${ }^{1}$, Clair Eccleston ${ }^{1}$, Gary P. Hubbard ${ }^{1}$, Ian C. Kavanagh ${ }^{1}$, \\ Anne-Marie Minihane ${ }^{1}$, Peter D. Weinberg ${ }^{2}$ and Gerald Rimbach ${ }^{1 *}$ \\ ${ }^{1}$ Hugh Sinclair Human Nutrition Unit, School of Food Biosciences, University of Reading, \\ ${ }^{2}$ School of Animal and Microbial Sciences, The University of Reading, Reading, UK
}

(Received 18 July 2002 - Revised 20 November 2002 - Accepted 6 December 2002)

\begin{abstract}
There has been much recent interest in the cardiovascular benefits of dietary isoflavones. The aim of the present in vitro studies was to investigate potential anti-thrombogenic and antiatherogenic effects of the isoflavones genistein and daidzein in platelets, macrophages and endothelial cells. Pre-treatment with either isoflavone inhibited collagen-induced platelet aggregation in a dose-dependent manner. In a macrophage cell line (RAW 264.7) activated with interferon $\gamma$ plus lipopolysaccharide, both isoflavones were found to inhibit NO production and tumour necrosis factor $\alpha(\mathrm{TNF}-\alpha)$ secretion dose-dependently, but they did not affect mRNA levels for inducible nitric oxide synthase and cyclo-oxygenase-2. Both isoflavones also dose-dependently decreased monocyte chemoattractant protein- 1 secretion induced by TNF- $\alpha$ in human umbilical vein endothelial cells. Compared with daidzein, genistein exerted greater inhibitory effects for all parameters studied. The present data contributes to our knowledge on the molecular mechanisms by which isoflavones may protect against coronary artery disease. Further studies are required to determine whether the effects of isoflavones observed in the current in vitro studies are relevant to the aetiology of coronary artery disease in vivo.
\end{abstract}

Genistein: Daidzein: Platelet aggregation: Arteriosclerosis

The Food and Drug Administration (FDA) in the USA has recently approved a health claim for soya since laboratory investigations, clinical trials and epidemiological data indicate that a high soya consumption is associated with a lower risk of coronary artery disease (Vitolins et al. 2001). Soya products contain a significant amount of isoflavones, with genistein and daidzein (and their corresponding glycosides) being the most abundant. Isoflavones are members of the broad class of plant polyphenols, which have been shown to have benefits in the prevention of atherogenesis. The average dietary intake of isoflavones in European countries is $<1 \mathrm{mg} / \mathrm{d}$ (Setchell \& Cassidy, 1999) whereas in Eastern countries such as Japan intakes of $20-50 \mathrm{mg} / \mathrm{d}$ are common (Nagata et al. 1998). Although there is substantial evidence to indicate that it is the isoflavone fraction that provides the anti-thrombogenic and anti-atherogenic effects of soya, the mechanisms by which isoflavones exert these influences remain only partly understood.
Previous work has indicated that isoflavones exhibit free radical-scavenging action (Ruiz-Larrea et al. 1997; Arora et al. 1998), may increase the activity of antioxidant enzymes such as catalase, superoxide dismutase, glutathione peroxidase and glutathione reductase, inhibit superoxide generation by xanthine or xanthine oxidase (Wei et al. 1995), and inhibit the oxidation of LDL (Kerry \& Abbey, 1998). Furthermore, the consumption of isoflavones significantly increases the lag time of LDL oxidation in human volunteers (Wiseman et al. 2000). Genistein and daidzein have also been shown to protect human endothelial cells against the cytotoxic effects of oxidized LDL (Kapiotis et al. 1997). In addition, it has been recently demonstrated that genistein and daidzein at physiologically achievable concentrations significantly elevate glutathione levels in human endothelial cells (Guo et al. 2002).

The purpose of the present study was to expand current knowledge concerning the molecular mechanisms by

\footnotetext{
Abbreviations: COX-2, cyclo-oxygenase-2; GAPDH, glycerinaldehyde 3-phosphate dehydrogenase; HUVEC, human umbilical vein endothelial cells; IFN$\gamma$, interferon $\gamma$; iNOS, inducible nitric oxide synthase; LPS, lipopolysaccharide; MCP-1, monocyte chemoattractant protein-1; TNF- $\alpha$, tumour necrosis factor $\alpha$.

* Corresponding author: Dr Gerald Rimbach, fax +44 118931 0080, email G.H.Rimbach@reading.ac.uk
} 
which genistein and daidzein might exert anti-thrombogenic and anti-atherogenic effects. More specifically, we have investigated in vitro the impact of these isoflavones on: (i) platelet aggregation in whole human blood; (ii) NO production, tumour necrosis factor $\alpha$ (TNF- $\alpha)$ secretion and gene expression of both inducible nitric oxide synthase (iNOS) and cyclo-oxygenase-2 (COX-2) in a murine macrophage cell line; (iii) monocyte chemoattractant protein-1 (MCP-1) secretion by human umbilical vein endothelial cells (HUVEC).

\section{Materials and methods}

\section{Platelet isolation and platelet aggregation measurement}

Venous blood samples were obtained from volunteers within the Hugh Sinclair Unit of Human Nutrition at the University of Reading. Blood for platelet aggregation studies was drawn into $4.5 \mathrm{ml}$ sodium citrate vacutainer tubes (Becton Dickinson, Plymouth, UK) and kept at room temperature until analysis. Platelet aggregation studies were performed in a two-channel whole-blood impedance aggregometer (Model 590; Chronolog Corporation, Labmedics Ltd., Cheshire, UK). Whole blood $(500 \mu \mathrm{l})$ was diluted 1:1 with PBS, placed in cuvettes with a stir bar and warmed to $37^{\circ} \mathrm{C}$. Isoflavones $(2 \mu \mathrm{l})$ or dimethyl sulfoxide $(2 \mu \mathrm{l})$ as the control were then added and the samples stirred for $10 \mathrm{~s}$. The samples were incubated with the isoflavones for $10 \mathrm{~min}$. The aggregometer's impedance probe was placed into the warmed blood, and the baseline impedance was set to zero on the chart recorders. Collagen $(1.5 \mu \mathrm{g} /$ $\mathrm{ml}$ ) was added to the cuvette at time zero and the impedance was increased proportional to the amount of platelet aggregation on the impedance probe. Maximum aggregation was measured at $6 \mathrm{~min}$, with the extent of aggregation expressed in $\Omega$ of impedance using Aggrolink software (Chronolog Corporation, Labmedics Ltd., Cheshire, UK). Control aggregation curves were obtained in the absence of genistein and daidzein and were compared with the curves obtained in the presence of the isoflavones. The results were used to calculate the percentage inhibition (100percentage of aggregation).

\section{Endothelial cells}

HUVEC (Biowhittaker, Wokingham, UK) were grown in Medium 199 (Autogen Bioclear, Calne, UK) supplemented with $20 \%$ heat-inactivated FBS, 2 mM-L-glutamine, $1 \%$ Dglucose, $20 \mathrm{~mm}$-4-(2-hydroxyethyl)-1-piperazine ethanesulfonic acid (HEPES), penicillin $(100 \mathrm{U} / \mathrm{ml})$ and streptomycin $(100 \mu \mathrm{g} / \mathrm{ml})$. Endothelial cell growth factor $(1 \times)$ (Sigma, Poole, UK) was added to fresh culture medium after each media change. HUVEC were utilized for experiments at 90-100\% apparent confluence within passages 2 to 4. Passages were performed according to standardized protocols and by diluting the cell population 1:3 (Rimbach et al. 2001).

\section{Macrophages}

RAW 264.7 cells, a murine cell line of monocyte-macrophages (obtained from the European Collection of Cell
Culture, Salisbury, UK), were maintained at $37^{\circ} \mathrm{C}$ in $5 \%$ (v/v) $\mathrm{CO}_{2}$ according to standard protocols (Rimbach et al. $2000 a$ ). This murine cell line was chosen as it represents an established model for examining determinants of NO production, which is detectable by the Griess reaction. RAW 264.7 cells were cultured in Dulbecco's modified Eagle medium (DMEM) containing $10 \%$ heat-inactivated fetal bovine serum (FBS), $2 \mathrm{mM}$-L-glutamine, $1 \mathrm{mM}$ sodium pyruvate, penicillin $(100 \mathrm{U} / \mathrm{ml})$ and streptomycin $(100 \mu \mathrm{g} / \mathrm{ml})$, and stimulated with $500 \mathrm{ng}$ lipopolysaccharide (LPS)/ml and $100 \mathrm{U}$ interferon $\gamma(\mathrm{IFN}-\gamma) / \mathrm{ml}$ (Sigma, Poole, UK).

\section{Cell viability}

The uptake of the neutral red dye was used to measure cell viability as described previously (Valacchi et al. 2001). Cells were pre-treated with genistein and daidzein for $24 \mathrm{~h}$. Before activation with either IFN- $\gamma$ plus LPS or TNF- $\gamma$, cells were washed twice with PBS in order to avoid any chemical interaction between the isoflavones and the activators. Cytotoxicity was measured $24 \mathrm{~h}$ post treatment with either IFN- $\gamma$ plus LPS or TNF- $\alpha$. The culture medium was removed and replaced with fresh medium containing $60 \mu \mathrm{g}$ neutral $\mathrm{red} / \mathrm{ml}$ (Fisher Scientific, Leicestershire, UK) for $3 \mathrm{~h}$ at $37^{\circ} \mathrm{C}$. Following incubation with the neutral red dye, the medium was removed and the cells extracted using a solution comprising ethanol, water and glacial acetic acid (50:49:1, v/v). Absorbance was recorded at $540 \mathrm{~nm}$ using a microplate reader.

For all cell culture experiments genistein and daidzein (Sigma, Poole, UK) were dissolved in dimethyl sulfoxide and stored at $-80^{\circ} \mathrm{C}$. The final dimethyl sulfoxide concentration in the cell culture medium was $0.1 \%(\mathrm{v} / \mathrm{v})$ or less. Pre-treatment of RAW 264.7 macrophages with up to $100 \mu \mathrm{M}$ and treatment of HUVEC with up to $50 \mu \mathrm{M}$ genistein and daidzein did not affect cell viability.

\section{Nitric oxide production}

NO production was assessed by measurement of both total $\mathrm{NO}$ (nitrite and nitrate) and nitrite $\left(\mathrm{NO}_{2}^{-}\right)$in the medium. Total NO production was measured using an NO colorimetric assay kit (Boehringer Mannheim, Germany) under the conditions recommended by the supplier. Nitrite production was determined by the Griess reaction. Supernatant fractions of cultured macrophages were collected and deproteinised with $0 \cdot 3 \mathrm{M}-\mathrm{NaOH}$ and $0 \cdot 3 \mathrm{M}-\mathrm{ZnSO}_{4}$. An equal volume of the Griess reagent (1\% sulfanilamide$0.1 \% N$-(1-naphthyl)-ethylenediamine dihydro-chloride$2.5 \% \mathrm{H}_{3} \mathrm{PO}_{4}$ ) and the deproteinised sample were incubated for $10 \mathrm{~min}$ at room temperature. Nitrite concentration was determined by measuring the absorbance at $548 \mathrm{~nm}$ against a standard curve for sodium nitrite (Park et al. 2000).

\section{Reverse transcription polymerase chain reaction}

Total RNA was extracted from cells following the method of Chomczynski \& Sacchi (1987). Reverse transcription was performed using an RNA polymerase chain reaction kit (Omniscript Reverse Transcriptase Kit; Qiagen Ltd., 
Crawley, UK) with $2 \mu \mathrm{g}$ total RNA used to synthesise cDNA. Reverse transcriptase-generated cDNA, encoding iNOS, COX-2 and glycerinaldehyde 3-phosphate dehydrogenase (GAPDH), was amplified using polymerase chain reaction. Oligonucleotide primers that correspond to the murine macrophage iNOS, COX-2 and murine GAPDH cDNA were used (MWG-Biotech Ltd., Milton Keynes, UK). Polymerase chain reaction was performed using an RNA polymerase chain reaction kit (Applied Biosystems, Warrington, UK). The reaction volume was $12.5 \mu \mathrm{l}$ containing (final concentration): polymerase chain reaction buffer $(1 \times)$; deoxynucleotide $\left(0.2 \mathrm{~mm}\right.$ each); $\mathrm{MgCl}_{2}$ $(1.5 \mu \mathrm{M})$; AmpliTaq Gold DNA polymerase (0.625U); oligonucleotide primer (1 $\mu \mathrm{M}$ each); reverse transcriptase products. Further details of the polymerase chain reaction analysis are summarized in Table 1. The number of polymerisation cycles was chosen within the range providing linear amplification of the cDNA. For each gene increasing amounts of cDNA were amplified in order to check the linearity of the resulting signal. An extension step at $72^{\circ} \mathrm{C}$ for 10 min was conducted after completion of $25-35$ cycles. A $12 \mu \mathrm{l}$ sample from each polymerase chain reaction was electrophoresed in a $1.5 \%(\mathrm{w} / \mathrm{v})$ agarose gel containing $0.2 \mu \mathrm{g}$ ethidium bromide/ml. The gel was quantified under u.v. light using a gel documentation system (SynGene, Cambridge, UK).

\section{Tumour necrosis factor $\alpha$ and monocyte chemoattractant protein-1 secretion}

TNF- $\alpha$ secretion (BioScource Europe SA, Nivelles, Belgium) in RAW 264.7 macrophages and MCP-1 secretion (R\&D Systems Europe, Abingdon, UK) in HUVEC were measured using commercially available ELISA kits.

\section{Statistical analysis}

Data are presented as mean values and standard errors of the mean of between three and five independent experiments performed in triplicate. The data were checked for normality and log-transformed where appropriate. Statistical analysis was carried out using ANOVA and Student's $t$ test, and the Kruskal-Wallis and the Mann-Whitney U test (SPSS for Windows version 10.0). Differences were considered significant if $P<0.05$. Inhibitory concentration values were calculated using Prism for Windows (version 3.0). Inhibitory concentration values describe the concentration of genistein and daidzein causing $50 \%$ inhibition.
A non-linear regression model was adapted with a variable hillslope and fixed constants at $0 \%$ and $100 \%$ inhibition.

\section{Results}

Human whole blood platelet aggregation in vitro

As shown in Fig. 1, both genistein and daidzein inhibited human platelet aggregation in vitro in a dose-dependent manner. Statistically significant differences compared with controls were evident for genistein at concentrations of $25 \mu \mathrm{M}$ and above $(P<0 \cdot 05)$. Daidzein significantly inhibited platelet aggregation at concentrations $\geq 50 \mu \mathrm{M}$ $(P<0 \cdot 01)$. Synergistic effects between genistein and daidzein were tested as follows: $2.5 \mu \mathrm{M}$-genistein plus $2.5 \mu \mathrm{M}$-daidzein $v$. $5 \mu \mathrm{M}$-genistein; $5 \mu \mathrm{M}$-genistein plus $5 \mu \mathrm{M}$-daizein $v$. $10 \mu \mathrm{M}$-genistein; $25 \mu \mathrm{M}$-genistein plus $25 \mu \mathrm{M}$-daidzein $v .50 \mu \mathrm{M}$-genistein. No synergistic effects between genistein and daidzein on platelet aggregation were evident.

\section{Nitric oxide production and tumour necrosis factor secretion in murine macrophages}

Twenty-four hours after treatment with IFN- $\gamma$ plus LPS murine macrophages showed an increase in the levels of $\mathrm{NO}_{2}^{-}$in the culture medium from 5 to about $80 \mu \mathrm{M} / 10^{6}$ cells (Fig. 2 (A)); $60-65 \%$ of the total NO was produced as nitrite. Pre-treatment of RAW 264.7 with genistein or daidzein for $24 \mathrm{~h}$ was associated with a dose-dependent decrease of nitrite production (Fig. 2 (B)). Genistein significantly $(P<0.01)$ inhibited NO production at concentrations $\geq 5 \mu \mathrm{M}$. However, for daidzein a 10 -fold higher concentration was necessary in order to induce a statistically significant $(P<0.005)$ inhibition in the production of NO.

Similarly both isoflavones inhibited the secretion of the pro-inflammatory cytokine TNF- $\alpha$ in a dose-dependent manner (Fig. 3). For genistein and daidzein a statistically significant $(P<0.05)$ inhibition of TNF- $\alpha$ secretion compared with controls was evident at concentrations of $\geq 50 \mu \mathrm{M}$.

\section{Inducible nitric oxide synthase and cyclo-oxygenase-2 gene expression in murine macrophages}

As shown in Fig. 4, non-activated RAW 264.7 did not express detectable levels of iNOS mRNA. However, treatment with IFN- $\gamma$ plus LPS induced a substantial increase in iNOS gene expression. Under these experimental conditions

Table 1. Experimental conditions for reverse transcription polymerase chain reaction (PCR) analysis of inducible nitric oxide synthase (iNOS), cyclo-oxygenase-2 (COX-2) and glycerinaldehyde 3-phosphate dehydrogenase (GAPDH)

\begin{tabular}{|c|c|c|}
\hline Gene & Primer sequence & PCR conditions* \\
\hline GAPDH & $\begin{array}{l}5^{\prime} \text { TGAAGGTCGGTGTGAACGGATTTGGC } 3^{\prime} \\
5^{\prime} \text { CATGTAGGCCATGAGGTCCACCAC } 3^{\prime}\end{array}$ & $1 \mathrm{~min}$ at $95^{\circ} \mathrm{C}, 1 \mathrm{~min}$ at $62^{\circ} \mathrm{C}, 1 \mathrm{~min}$ at $72^{\circ} \mathrm{C}$, thirty cycles \\
\hline iNOS & $\begin{array}{l}5^{\prime} \text { CCCTTCCGAAGTTTCTGGCAGCAGC } 3^{\prime} \\
5^{\prime} \text { GGCTGTCAGAGCCTCGTGGCTTTGG } 3^{\prime}\end{array}$ & $1 \mathrm{~min}$ at $95^{\circ} \mathrm{C}, 1 \mathrm{~min}$ at $65^{\circ} \mathrm{C}, 1 \mathrm{~min}$ at $72^{\circ} \mathrm{C}$, twenty-seven cycles \\
\hline cox-2 & $\begin{array}{l}5^{\prime} \text { TTTGTTGAGTCATTCACCAGACAGAT } 3^{\prime} \\
5^{\prime} \text { CAGTATTGAGGAGAACAGATGGGATT } 3^{\prime}\end{array}$ & $1 \mathrm{~min}$ at $95^{\circ} \mathrm{C}, 1 \mathrm{~min}$ at $55^{\circ} \mathrm{C}, 1 \mathrm{~min}$ at $72^{\circ} \mathrm{C}$, thirty cycles \\
\hline
\end{tabular}

*Denaturation, annealing, elongation, number of cycles. 


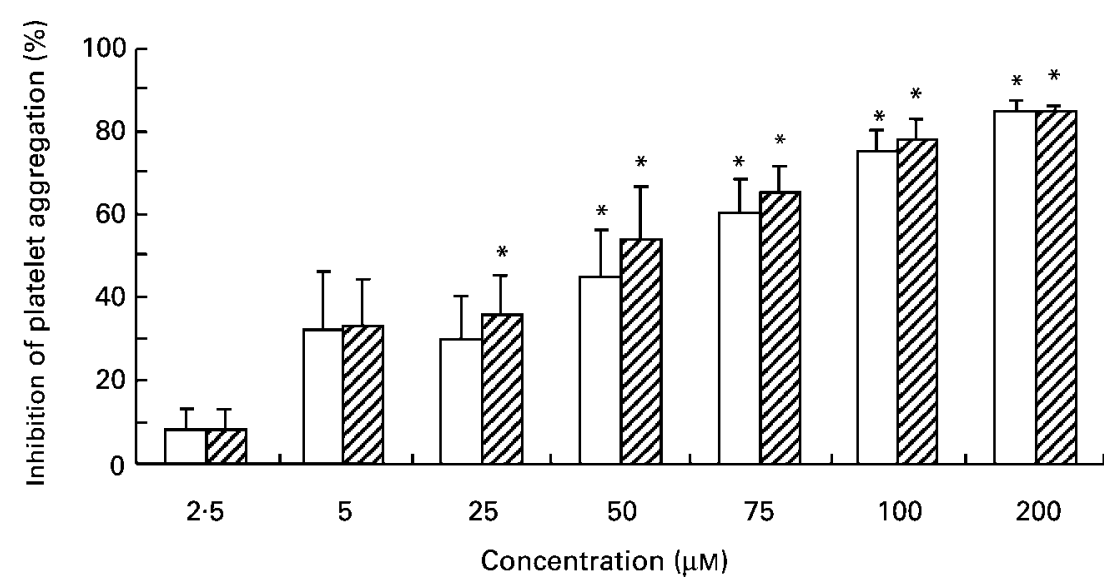

Fig. 1. Effect of genistein (卿) and daidzein $(\square)$ on collagen-induced $(1.5 \mu \mathrm{g} / \mathrm{ml})$ human platelet aggregation in vitro. Human platelets were treated with different concentrations of genistein and daidzein $(2 \cdot 5,5,25,50,75,100$ and $200 \mu \mathrm{M})$ and platelet aggregation was measured with a whole blood aggregometer. Control values were obtained in the absence of genistein and daidzein. Data were derived from five independent experiments performed in triplicate and expressed as mean values, with standard errors of the mean being represented by vertical bars. * Mean value was significantly different from the control $(P<0.05)$.

neither isoflavone had an effect on iNOS mRNA levels in activated macrophages.

Non-activated cells expressed low, although detectable, levels of COX- 2 mRNA. Cells activated with IFN- $\gamma$ plus LPS expressed higher COX-2 mRNA levels. Pre-treatment of RAW 264.7 macrophages with genistein or daidzein did not result in any differences in COX-2 mRNA levels relative to non-treated cells. In all experiments the housekeeping gene GAPDH was equally expressed, irrespective of treatment.

\section{Monocyte chemoattractant protein-1 secretion in human umbilical vein endothelial cells}

Confluent monolayers of primary HUVEC were pre-treated with genistein and daidzein for $24 \mathrm{~h}$. The cells were activated for $24 \mathrm{~h}$ with TNF- $\alpha$ and the secretion of MCP-1 into the medium was examined using a sandwich ELISA. A statistically significant decrease in the secretion of MCP-1 into the culture medium compared with controls was evident at genistein concentrations $\geq 25 \mu \mathrm{M}$ $(P<0.05)$ and daidzein concentrations $\geq 50 \mu \mathrm{M}(P<0.01)$ respectively (Fig. 5).

\section{Inhibitory concentration values for genistein and daidzein}

Table 2 provides an overview of the inhibitory concentration values for genistein and daidzein with respect to platelet aggregation, monocyte function and MCP-1 secretion. Both isoflavones tested showed inhibitory effects with respect to human platelet aggregation in vitro, NO production and TNF- $\alpha$ secretion in murine monocytes in addition to MCP-1 secretion in human endothelial cells. Compared with daidzein, genistein exerted greater inhibitory effects for all parameters studied.

\section{Discussion}

Platelets, macrophages and endothelial cells were chosen for investigation in the present study as all three cell types are thought to play critical roles in the pathogenesis of thrombosis and atherosclerosis. Endothelial cells appear to be involved from the earliest stages. At sites of endothelial injury, perhaps induced by intimal accumulation and modification of lipid, these cells produce chemokines such as MCP-1 which attract monocytes. Subsequently the monocytes are activated to produce pro-inflammatory molecules such as TNF- $\alpha$ and NO, and accumulate lipids to become the foam cells characteristic of fatty streaks. Platelets may be also involved in these early stages of atherosclerosis, in response to the endothelial damage, and are clearly important in the aetiology of thrombogenesis (Gibbons \& Dzau, 1996).

\section{Isoflavones and platelet aggregation}

Collagen was used as an agonist in the in vitro aggregation protocol, since it participates in the early steps of platelet activation in vivo. Although the exact mechanism of collagen-induced signal transduction is not completely known, collagen most likely binds to the integrin glycoprotein Ia-IIa on the platelet surface, thereby inducing signalling events in platelets. This process results in an augmentation in cytosolic $\mathrm{Ca}^{2+}$ (Poole \& Watson, 1995), activation of both protein kinase $\mathrm{C}$ and phospholipase $\mathrm{A}_{2}$, and the platelet release reaction. The secretion of adenosine diphosphate and thromboxane $\mathrm{A}_{2}$ is the final step in platelet activation and leads to further recruitment of platelets and increased aggregation. Recently, integrin glycoprotein VI has been identified as a further receptor for collagen-induced signal transduction in platelets via a tyrosine kinase-dependent phosphorylation of phospholipase $\mathrm{C}$ (Pignatelli et al. 1998).

The results of the present study clearly show that both genistein and daidzein have anti-aggregatory activity in human platelets in vitro. This finding is consistent with earlier reports that the consumption of soya protein and its isoflavone-enriched fraction lowers platelet aggregation in rats (Peluso et al. 2000). The exact molecular mechanisms by which isoflavones affect platelet aggregation are unclear 


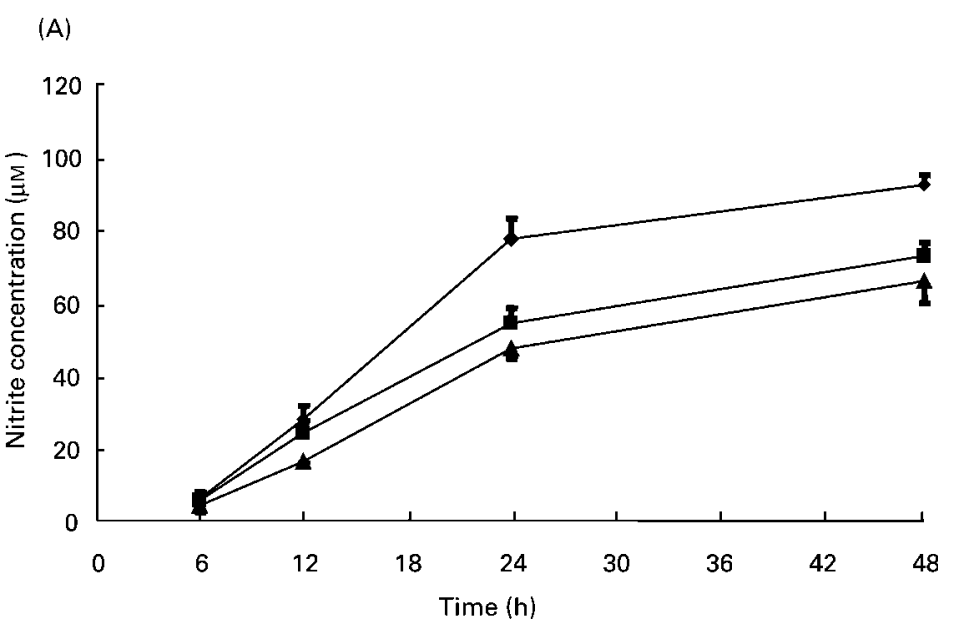

(B)

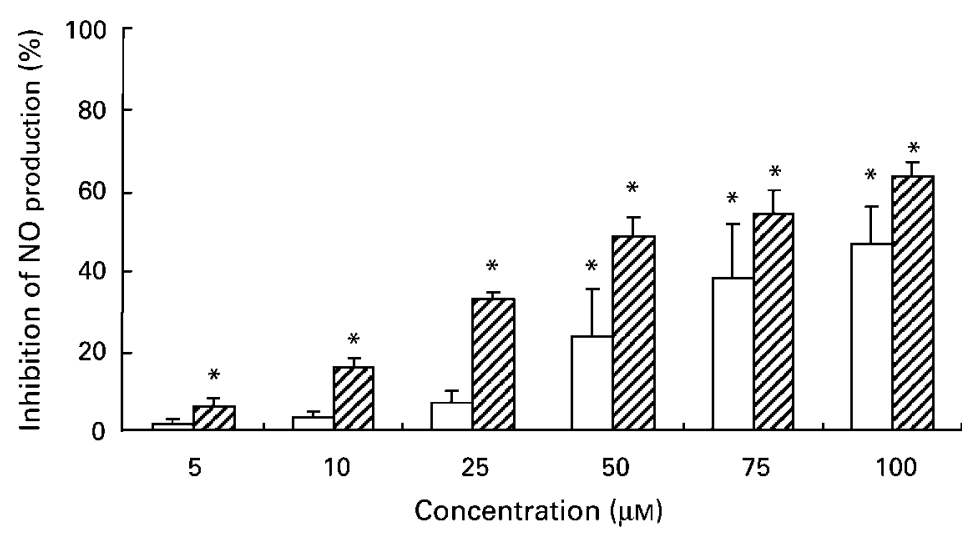

Fig. 2. (A) Effect of genistein (- $\Delta-$ ) and daidzein (- - -) on NO production over a $48 \mathrm{~h}$ time period in activated murine RAW $264.7 \mathrm{macrophages.}$ The cells were treated with $50 \mu \mathrm{M}$-genistein and -daidzein for $24 \mathrm{~h}$ and then activated with interferon $\gamma$ (IFN- $\gamma ; 100 \mathrm{U} / \mathrm{ml})$ plus lipopolysaccharide (LPS; $500 \mathrm{ng} / \mathrm{ml}$ ). At the end of the incubation period a sample of the medium was removed for measuring nitrite by the Griess reaction. Data were derived from three independent experiments performed in triplicate and are expressed as mean values, with standard errors of the mean being represented by vertical bars. * Mean values of the IFN- $\gamma$ plus LPS-treated group were significantly different compared with controls (- -$)(P<0.05)$. (B) Effect of genistein $(\mathbb{Q})$ and daidzein $(\square)$ on NO production in murine RAW 264.7 macrophages measured $24 \mathrm{~h}$ after activation. The cells were pre-treated with genistein and daidzein $(5,10,25,50,75,100 \mu \mathrm{M})$ for $24 \mathrm{~h}$ and then activated with interferon $\gamma($ IFN$\gamma ; 100 \mathrm{U} / \mathrm{ml}$ ) plus lipopolysaccharide (LPS; $500 \mathrm{ng} / \mathrm{ml}$ ). Data were compared with activated controls (average nitrite production 86.7 (SEM 6.1 ) $\mu M=100 \%$ reference) which were not treated with isoflavones. Data were derived from five independent experiments performed in triplicate and are expressed as mean values, with standard errors of the mean being represented by vertical bars. ${ }^{*}$ Mean values of the IFN- $\gamma$ plus LPS-treated group were significantly different compared with controls $(P<0.05)$.

and currently under investigation. Apart from protein tyrosine kinase inhibition (Nakashima et al. 1991) within the cyclo-oxygenase pathway, several other reported molecular effects of flavonoids could have influenced platelet function in the present study. The modification of platelet cyclic AMP via the inhibition of phosphodiesterase activity is the most supported pathway for anti-aggregatory effects of flavonoids (Beretz et al. 1982). Inhibition of lipoxygenase activity, as demonstrated principally for myricetin and quercetin (Landolfi et al. 1984), is another possible mechanism. Stimulation of adenylate cyclase, leading to increased cyclic AMP levels, has been proposed as a further anti-aggregatory signal transduction pathway (Packham \& Mustard, 1977).

In addition, the antioxidant character of isoflavones may play a role in inhibiting platelet aggregation. Pignatelli et al. (1998) showed that collagen-induced platelet aggregation was associated with the production of $\mathrm{H}_{2} \mathrm{O}_{2}$ which acts as an important second messenger in platelets, stimulating both the phospholipase $\mathrm{C}$ pathway and the arachidonic acid metabolism. Consistent with this finding, platelets primed with non-activating concentrations of arachidonic acid or collagen were activated by nanomolar concentrations of $\mathrm{H}_{2} \mathrm{O}_{2}$ (Iuliano et al. 1994). Since isoflavones possess antioxidant properties (Ruiz-Larrea et al. 1997; Arora et al. 1998) and can scavenge radicals, this evidence that reactive oxygen species are involved in platelet stimulation suggests another anti-aggregatory mechanism. In comparison with daidzein the genistein molecule contains an additional hydroxyl group in the $\mathrm{C}_{5}$ position, possibly resulting in a higher antioxidant activity (Wei et al. 1995). This might explain why in the present study genistein has been demonstrated to be a more potent inhibitor of platelet aggregation than daidzein.

Furthermore, isoflavones have been shown to enhance NO production from the endothelium. NO is a potent 


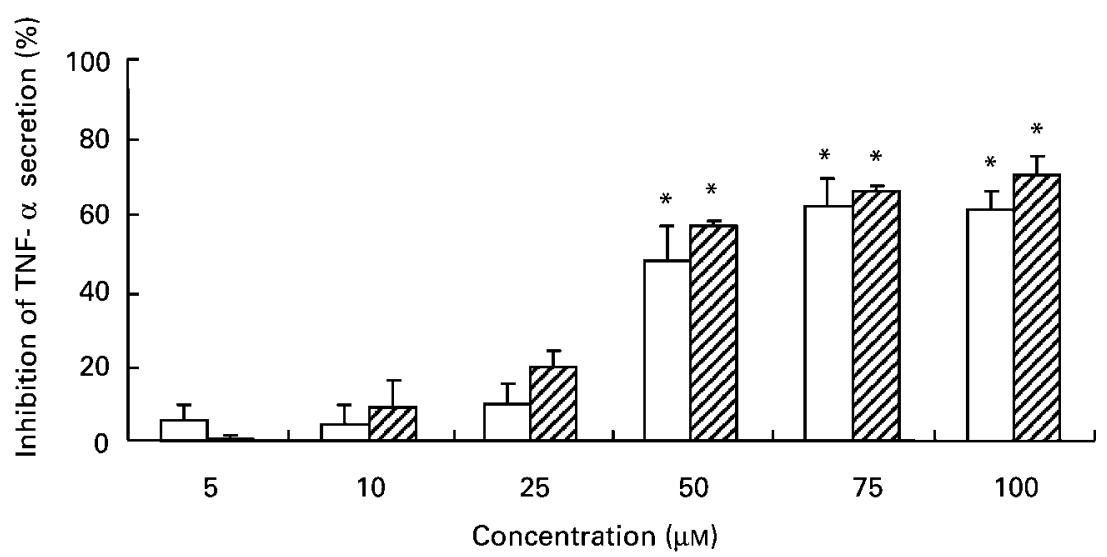

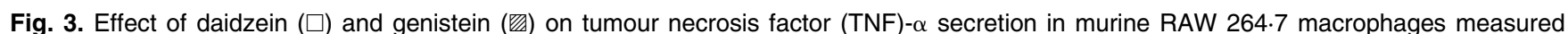
$24 \mathrm{~h}$ after activation. The cells were treated with genistein and daidzein $(5,10,25,50,75,100 \mu \mathrm{M})$ for $24 \mathrm{~h}$ and then activated with interferon $\gamma$ $($ IFN- $\gamma ; 100 \mathrm{U} / \mathrm{ml}$ ) plus lipopolysaccharide (LPS; $500 \mathrm{ng} / \mathrm{ml}$ ). At the end of the incubation period a sample of the medium was removed for measuring TNF- $\alpha$ secretion by ELISA. Data were compared with activated controls (average TNF- $\alpha$ production 14.4 (SEM 3.3$) \mathrm{ng} / \mathrm{ml}=100 \%$ reference) that were not treated with the isoflavones. Data were derived from five independent experiments performed in triplicate and are expressed as mean values, with standard errors of the mean being represented by vertical bars. * Mean values of the IFN- $\gamma$ plus LPS-treated group were significantly different compared with controls $(P<0.05)$.

inhibitor of platelet adhesion, aggregation and thrombosis and impaired platelet production of NO has been associated with acute coronary syndromes (Duffy et al. 2001). Thus genistein and daidzein may affect platelet aggregation via an NO-dependent signal transduction pathway, a potential mechanism, which is currently under investigation.
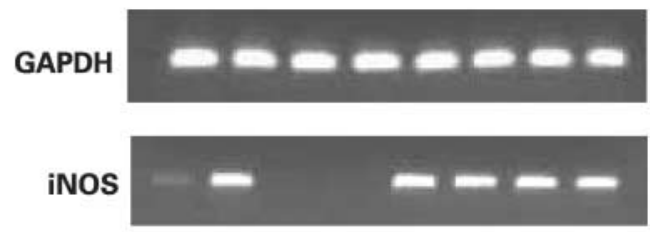

$\operatorname{cox}-2$
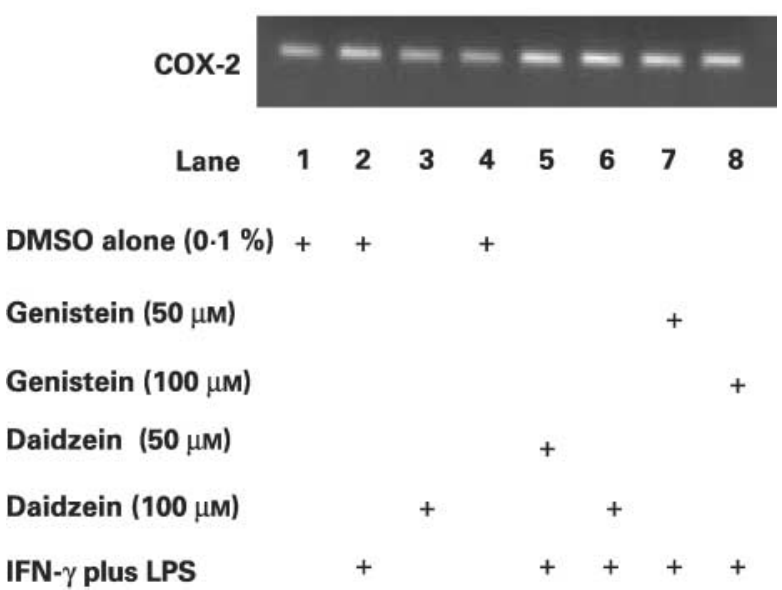

Fig. 4. Effect of genistein and daidzein on the expression of inducible nitric oxide synthase (iNOS) and cyclo-oxygenase-2 (COX-2) mRNA in activated macrophages. The cells were treated with $50 \mu \mathrm{M}$-genistein and -daidzein for $24 \mathrm{~h}$ and then activated with interferon $\gamma(\mathrm{IFN}-\gamma ; 100 \mathrm{U} / \mathrm{ml})$ plus lipopolysaccharide (LPS; $500 \mathrm{ng} / \mathrm{ml})$. The expression of mRNA of iNOS (6h after activation) and COX-2 (12 $\mathrm{h}$ after activation) was determined by reverse transcription polymerase chain reaction analysis. Glycerinaldehyde 3-phosphate dehydrogenase (GAPDH) was used as an internal control. One representative experiment, out of three, is presented. DMSO, dimethyl sulfoxide.

\section{Isoflavones and monocyte function}

Monocyte-derived macrophages are the principal inflammatory cell in atheromata. In early stages of atherosclerotic lesion formation, macrophages and endothelial cells interact to trigger a cycle of events that exacerbates endothelial dysfunction, resulting in a loss of haemostatic control (Tedesco et al. 1999). Activated macrophages generate large amounts of $\mathrm{NO}$ from L-arginine by the action of iNOS. NO is an important intracellular and intercellular regulator of many biological functions, including macrophage-mediated cytotoxicity (Ignarro, 1994; Beckman \& Koppenol, 1996). Cytokines such as IFN- $\gamma$ and other

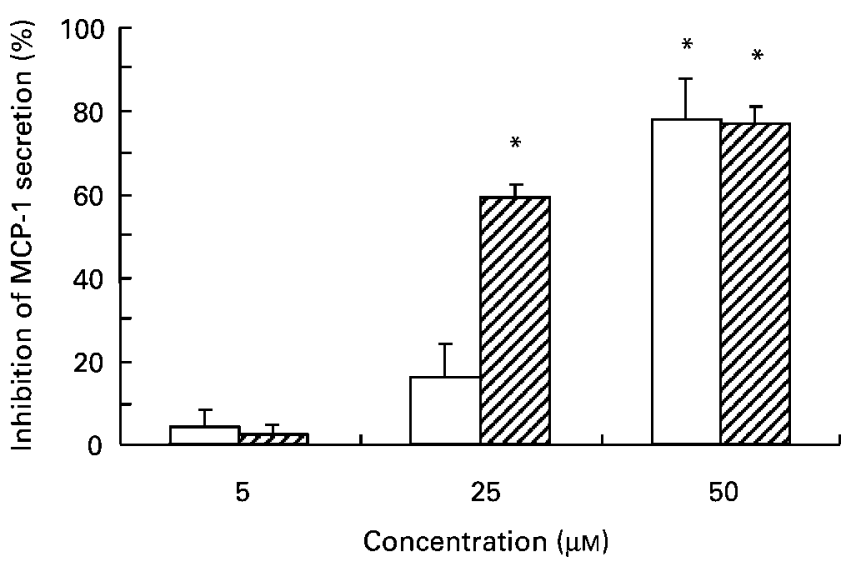

Fig. 5. Effect of genistein (四) and daidzein ( $\square$ ) on monocyte chemoattractant protein-1 (MCP-1) secretion in human umbilical vein endothelial cells measured $24 \mathrm{~h}$ after activation. The cells were pretreated with genistein and daidzein $(5,25,50 \mu \mathrm{M})$ for $24 \mathrm{~h}$ and then activated with tumour necrosis factor $\alpha(40 \mathrm{ng} / \mathrm{ml})$. Data were compared with activated controls (average MCP-1 secretion 29.3 (SEM $3.8) \mathrm{ng} / \mathrm{ml}=100 \%$ reference) that were not treated with isoflavones. Data were derived from two independent experiments performed in triplicate and expressed as mean values, with standard errors of the mean being represented by vertical bars. * Mean values of the IFN- $\gamma$ plus LPS-treated group were significantly different compared with controls $(P<0.05)$. 
Table 2. Inhibitory concentration values of genistein and daidzein with respect to platelet aggregation, NO production and tumour necrosis factor (TNF)- $\alpha$ secretion in macrophages as well as monocyte chemoattractant protein (MCP)-1 secretion in human endothelial cells*

\begin{tabular}{|c|c|c|c|c|}
\hline \multirow{2}{*}{$\begin{array}{l}\text { Cell type... } \\
\text { Parameter... }\end{array}$} & \multirow{2}{*}{$\frac{\text { Platelets }}{\text { Platelet aggregation }}$} & \multicolumn{2}{|c|}{ Macrophages } & \multirow{2}{*}{$\frac{\text { Endothelial cells }}{\text { MCP-1 secretion }}$} \\
\hline & & NO production & TNF- $\alpha$ secretion & \\
\hline Genistein $(\mu \mathrm{M})$ & $30 \cdot 3$ & $57 \cdot 9$ & $52 \cdot 9$ & $29 \cdot 4$ \\
\hline Daidzein ( $\mu \mathrm{M})$ & $38 \cdot 8$ & $106 \cdot 5$ & $64 \cdot 2$ & $37 \cdot 3$ \\
\hline
\end{tabular}

* Inhibitory concentration values describe the concentration of the isoflavones causing $50 \%$ inhibition. A non-linear regression model was adapted with a variable hillslope and fixed constants at $0 \%$ and $100 \%$ inhibition.

inflammatory stimuli such as bacterial LPS regulate the activity of iNOS in macrophages (Stuehr \& Marletta, 1987; Narumi et al. 1990). Overproduction of NO has been associated with oxidative stress and chronic inflammation (Moncada et al. 1991; Arteel et al. 1999).

In the present study genistein and daidzein significantly inhibited IFN- $\gamma$ plus LPS-induced NO production in RAW 264.7 macrophages. iNOS mRNA levels remained unchanged by the isoflavone treatment, suggesting that the inhibitory effect is post-transcriptional. In contrast to our findings Sheu et al. (2001) did find an inhibitory effect of genistein and daidzein on LPS-induced expression of the iNOS gene in macrophages, but their co-incubation of LPS and isoflavones may have given rise to this effect since polyphenols suppress LPS activity (Azumi et al. 1997). Thus inhibition of iNOS expression might have been caused by a direct interaction of these compounds with the LPS molecule, rather than a direct effect on the cell. In the present investigation macrophages were pre-incubated with genistein and daidzein for $24 \mathrm{~h}$ and were then washed twice with PBS before the addition of IFN- $\gamma$ and LPS in order to avoid any direct chemical interaction.

In recent years, a role of COX-2 in atherogenesis has been identified. Immunocytochemical studies have shown increased COX-2 expression by macrophages in atherosclerotic lesions of patients with coronary artery disease (Baker et al. 1999). Furthermore, the possibility of cross-talk between iNOS and COX-2 has been recently suggested and a colocalization of COX-2 and iNOS has been demonstrated in animal models of inflammation (Mitchell et al. 1995). Since NO has been shown to enhance COX-2 activity both in vitro and in vivo, COX-2 mRNA levels were determined by reverse transcription polymerase chain reaction in the current study. However, under the conditions investigated enhanced production of NO in activated macrophages was not accompanied by an up regulation of COX-2 gene expression.

\section{Isoflavones and endothelial monocyte chemoattractant protein-1 secretion}

MCP-1 is a CC-chemokine consisting of seventy-six amino acids. This molecule may play a key role in atherogenesis since it is involved in the recruitment of monocytes and Tcells into the arterial wall (Kowala et al. 2000; Wang et al. 2000). MCP-1 mRNA has been detected in atherosclerotic lesions by in situ hybridization (Nelken et al. 1991; Ylä-Herttuala et al. 1991). Furthermore a decrease in atherosclerotic lesion size is seen in mice deficient of the
MCP-1 receptor CCR-2, and fewer macrophages and monocytes are present in their aortas (Boring et al. 1998). Therapeutic drugs and dietary factors targeting MCP-1 and/or its receptor may prove useful in the prevention of atherosclerotic lesion development. In the present study genistein and daidzein dose-dependently down regulated MCP-1 secretion, indicating that both isoflavones might have the potential to inhibit monocyte infiltration into the arterial wall. It is known that the expression of MCP-1 is regulated at the transcriptional level (Rimbach et al. 2000b). Therefore it is hypothesized that genistein and daidzein may regulate $\mathrm{TNF}-\alpha$-induced MCP-1 expression through transcription factors such as nuclear factor $\kappa \mathrm{B}$ and activator protein-1, present in the promoter region of the MCP-1 gene.

In conclusion, genistein and daidzein have been shown to suppress aggregation of platelets, NO production and TNF$\alpha$ secretion by murine macrophages, and MCP-1 secretion by human endothelial cells, indicating a number of potential mechanisms for the cardioprotective effect of isoflavones. The present investigations have been carried out in vitro and dietary intervention studies are needed to elucidate the possible beneficial effects of isoflavones under in vivo conditions. Furthermore, the isoflavone concentrations used in the current study are higher than those achievable in plasma (Adlercreutz et al. 1993; Barnes, 1995). However it should be taken into account that modest changes in platelet aggregation as observed following relatively low isoflavone exposure may contribute to a significant reduction in cardiovascular risk. Finally, it should be noted that isoflavones do partially circulate as their glucuronidated and sulfated metabolites in the bloodstream (Holder et al. 1999). The formation of glucuronide and sulfate conjugates is likely to reduce the antioxidant and oestrogenic activity of isoflavones since important functional groups of the isoflavones molecule are masked. Therefore future research will have to examine the role of isoflavone metabolites in the prevention of coronary artery disease.

\section{Acknowledgements}

The authors would like to thank Dr Aedin Cassidy, Dr Kim Jackson and Dr Julie Lovegrove for their helpful discussion. B.A.E. is supported by grants from the Gen Foundation (UK registered charity no. 1071026) and Unilever R\&D, Colworth, UK. We are grateful to the Biotechnology and Biological Sciences Research Council (BBSRC) for funding this project. 


\section{References}

Adlercreutz H, Hamalainen E \& Gorbach S (1993) Dietary phytooestrogens and the menopause in Japan. Lancet 342, 1209-1210.

Arora A, Nair MG \& Strasburg GM (1998) Antioxidant activities of isoflavones and their biological metabolites in a liposomal system. Archives of Biochemistry and Biophysics 356, $133-141$.

Arteel GE, Briviba K \& Sies H (1999) Protection against peroxynitrite by cocoa polyphenol oligomers. FEBS Letters 445 , 226-230.

Azumi S, Tanimura A \& Tanamoto K (1997) A novel inhibitor of bacterial endotoxin derived from cinnamon bark. Biochemical and Biophysical Research Communications 234, 506-510.

Baker CS, Hall RJ, Evans TJ, Pomerance A, Maclouf J, Creminon C, Yacoub MH \& Polak JM (1999) Cyclooxygenase-2 is widely expressed in atherosclerotic lesions affecting native and transplanted human coronary arteries and colocalizes with inducible nitric oxide synthase and nitrotyrosine particularly in macrophages. Arteriosclerosis Thrombosis and Vascular Biology 19, 646-655.

Barnes S (1995) Effect of genistein on in vitro and in vivo models of cancer. Journal of Nutrition 125, 777S-783S.

Beckman JS \& Koppenol WH (1996) Nitric oxide, superoxide, and peroxynitrite: the good, the bad, and ugly. American Journal of Physiology 271, C1424-C1437.

Beretz A, Cazenave JP \& Anton R (1982) Inhibition of aggregation and secretion of human platelets by quercetin and other flavonoids: structure-activity relationships. Agents Actions 12, 382-387.

Boring L, Gosling J, Cleary M \& Charo IF (1998) Decreased lesion formation in CCR2-/- mice reveals a role for chemokines in the initiation of atherosclerosis. Nature 394, 894-897.

Chomczynski P \& Sacchi N (1987) Single-step method of RNA isolation by acid guanidinium thiocyanate-phenol-chloroform extraction. Annals of Biochemistry 162, 156-159.

Duffy SJ, Vita JA, Holbrook M, Swerdloff PL \& Keaney JF (2001) Effect of acute and chronic tea consumption on platelet aggregation in patients with coronary artery disease. Arteriosclerosis Thrombosis and Vascular Biology 21, 1084-1089.

Gibbons GH \& Dzau VJ (1996) Molecular Therapies For Vascular Diseases. Science 272, 689-693.

Guo Q, Rimbach G, Moini H, Weber S \& Packer L (2002) ESR and cell culture studies on free radical-scavenging and antioxidant activities of isoflavonoids. Toxicology 179, 171-180.

Holder CL, Churchwell MI \& Doerge DR (1999) Quantification of soy isoflavones, genistein and daidzein, and conjugates in rat blood using LC/ES-MS. Journal of Agricultural and Food Chemistry 47, 3764-3770.

Ignarro LJ (1994) Regulation of cytosolic guanylyl cyclase by porphyrins and metalloporphyrins. Advances in Pharmacology 26, 35-65.

Iuliano L, Pedersen JZ, Pratico D, Rotilio G \& Violi F (1994) Role of hydroxyl radicals in the activation of human platelets. European Journal of Biochemistry 221, 695-704.

Kapiotis S, Herrmann N, Held I, Seelos C, Ehringer H \& Gmeiner BMK (1997) Genistein, the dietary-derived angiogenesis inhibitor, prevents LDL oxidation and protects endothelial cells from damage by atherogenic LDL. Arteriosclerosis Thrombosis and Vascular Biology 17, 2868-2874.

Kerry N \& Abbey M (1998) The isoflavone genistein inhibits copper and peroxyl radical mediated low density lipoprotein oxidation in vitro. Atherosclerosis 140, 341-347.

Kowala MC, Recce R, Beyer S, Gu C \& Valentine M (2000) Characterization of atherosclerosis in LDL receptor knockout mice: macrophage accumulation correlates with rapid and sustained expression of aortic MCP-1/JE. Atherosclerosis 149, 323-330.

Landolfi R, Mower RL \& Steiner M (1984) Modification of platelet function and arachidonic acid metabolism by bioflavonoids. Structure-activity relations. Biochemical Pharmacology 33, $1525-1530$.

Mitchell JA, Larkin S \& Williams TJ (1995) Cyclooxygenase-2: regulation and relevance in inflammation. Biochemical Pharmacology 50, 1535-1542.

Moncada S, Palmer RM \& Higgs EA (1991) Nitric oxide: physiology, pathophysiology, and pharmacology. Pharmacological Revues 43, 109-142.

Nagata C, Takatsuko N, Kurisu Y \& Shimizu H (1998) Decreased serum total cholesterol concentration is associated with high intake of soy products in Japanese men and women. Journal of Nutrition 128, 209-213.

Nakashima S, Koike T \& Nozawa Y (1991) Genistein, a protein tyrosine kinase inhibitor, inhibits thromboxane A2-mediated human platelet responses. Molecular Pharmacology 39, $475-480$.

Narumi S, Finke JH \& Hamilton TA (1990) Interferon gamma and interleukin 2 synergize to induce selective monokine expression in murine peritoneal macrophages. Journal of Biological Chemistry 265, 7036-7041.

Nelken NA, Coughlin SR, Gordon D \& Wilcox JN (1991) Monocyte chemoattractant protein-1 in human atheromatous plaques. Journal of Clinical Investigation 88, 1121-1127.

Packham MA \& Mustard JF (1977) Clinical pharmacology of platelets. Blood 50, 555-573.

Park YC, Rimbach G, Saliou C, Valacchi G \& Packer L (2000) Activity of monomeric, dimeric, and trimeric flavonoids on NO production, TNF-alpha secretion, and NF-kappa B-dependent gene expression in RAW 264.7 macrophages. FEBS Letters 465, 93-97.

Peluso MR, Winters TA, Shanahan MF \& Banz WJ (2000) A cooperative interaction between soy protein and its isoflavone-enriched fraction lowers hepatic lipids in male obese Zucker rats and reduces blood platelet sensitivity in male Sprague-Dawley rats. Journal of Nutrition 130, 2333-2342.

Pignatelli P, Pulcinelli FM, Lenti L, Gazzaniga PP \& Violi F (1998) Hydrogen peroxide is involved in collagen-induced platelet activation. Blood 91, 484-490.

Poole AW \& Watson SP (1995) Regulation of cytosolic calcium by collagen in single human platelets. British Journal of Pharmacology 115, 101-106.

Rimbach G, Park YP, Guo Q, Moini H, Saliou C, Takayama K, Virgili F, Qureshi F \& Packer L (2000a) Nitric oxide synthesis and TNF-alpha secretion in RAW 264.7 macrophages: Mode of action of a fermented papaya preparation. Life Sciences 67, 679-694.

Rimbach G, Saliou C, Canali R \& Virgili F (2001) Interaction between cultured endothelial cells and macrophages: in vitro model for studying flavonoids in redox-dependent gene expression. Methods in Enzymology 335, 238-242.

Rimbach G, Valacchi G, Canali R \& Virgili F (2000b) Macrophages stimulated with IFN-gamma activate NF-kB and induce MCP-1 gene expression in primary human endothelial cells. Molecular and Cell Biology Research Communications 3, 238-242.

Ruiz-Larrea MB, Mohan AR, Paganga G, Miller NJ, Bolwell GP \& Rice-Evans CA (1997) Antioxidant activity of phytoestrogenic isoflavones. Free Radical Research 26, 63-70.

Setchell KDR \& Cassidy A (1999) Dietary isoflavones: biological effects and relevance to human health. Journal of Nutrition 129, $758 \mathrm{~S}-767 \mathrm{~S}$.

Sheu F, Lai HH \& Yen GC (2001) Suppression effect of soy isoflavones on nitric oxide production in RAW 264.7 
macrophages. Journal of Agricultural and Food Chemistry 49, 1767-1772.

Stuehr DJ \& Marletta MA (1987) Induction of nitrite/nitrate synthesis in murine macrophages by BCG infection, lymphokines, or interferon-gamma. Journal of Immunology 139, 518-525.

Tedesco F, Fischetti F, Pausa M, Dobrina A, Sim RB \& Daha MR (1999) Complement-endothelial cell interactions: pathophysiological implications. Molecular Immunology 36, 261-268.

Valacchi G, Rimbach G, Saliou C, Weber SU \& Packer L (2001) Effect of benzoyl peroxide on antioxidant status, NF-kappaB activity and interleukin-1alpha gene expression in human keratinocytes. Toxicology 165, 225-234.

Vitolins MZ, Anthony M \& Burke GL (2001) Soy protein isoflavones, lipids and arterial disease. Current Opinions in Lipidology 12, 433-437.

Wang Y, Rangan GK, Goodwin B, Tay YC \& Harris DC (2000)
Lipopolysaccharide-induced MCP-1 gene expression in rat tubular epithelial cells is nuclear factor-kappa B dependent. Kidney International 57, 2011-2022.

Wei H, Bowen R, Cai Q, Barnes S \& Wang Y (1995) Antioxidant and anti-promotional effects of the soybean isoflavone genistein. Proceedings of the Society of Experimental Biology 208, $124-130$.

Wiseman H, O'Reily JD, Adlercreutz H, Mallet AI, Bowey EA, Rowland IR \& Sanders TA (2000) Isoflavone phytoestrogens consumed in soy decrease $\mathrm{F}(2)$-isoprostane concentrations and increase resistance of low-density lipoprotein to oxidation. American Journal of Clinical Nutrition 72, 395-400.

Ylä-Herttuala S, Lipton BA, Rosenfeld ME, Särkioja T, Yoshimura T, Leonard EJ, Witztum JL \& Steinberg D (1991) Expression of monocyte chemoattractant protein 1 in macrophage-rich areas of human and rabbit atherosclerotic lesions. Proceedings of the National Academy of Sciences, USA 88, 5252-5256. 